\title{
Perioperative Materno-Fetal Morbimortality Related to the Caesarean in the Hospital Setting in Mali
}

\author{
Samaké Broulaye Massaoulé1, Tchaou Blaise Adélin², Goita Lassina1, Kassogué André1, \\ Bocoum Amadou ${ }^{3}$, Beye Seydina Alioune4, Monkam Yamadjeu Goliath1, Kéta Bakary', \\ Dabo Aminata1, Traoré Youssouf ${ }^{3}$, Tall Fadima Kouréissi' ${ }^{5}$, Dicko Hamadoun ${ }^{4}$, Kéita Mohamed ${ }^{4}$, \\ Tékété Ibrahim ${ }^{3}$
}

\author{
${ }^{1}$ Department of Intensive Care Unit at the University Hospital Gabriel Touré, Bamako, Mali \\ ${ }^{2}$ Department of Anesthesia-Resuscitation and Emergency, University and Departmental Hospital Center Borgou, Alibori, \\ Parakou, Benin \\ ${ }^{3}$ Department of Gyneocology at the University hospital Gabriel Touré, Bamako, Mali \\ ${ }^{4}$ Department of Emergency Care and Intensive Care Unit at the University hospital Kati, Mali \\ ${ }^{5}$ Department of Intensive Care Unit at the University Hospital Point G, Bamako-Mali, Bamako, Mali \\ Email: samakebroulaye@yahoo.fr
}

How to cite this paper: Massaoulé, S.B., Adélin, T.B., Lassina, G., André, K., Amadou, B., Alioune, B.S., Goliath, M.Y., Bakary, K., Aminata, D., Youssouf, T., Kouréissi, T.F., Hamadoun, D., Mohamed, K. and Ibrahim, T. (2020) Perioperative Materno-Fetal Morbimortality Related to the Caesarean in the Hospital Setting in Mali. Open Journal of Obstetrics and Gynecology, 10, 1693-1701. https://doi.org/10.4236/ojog.2020.10120153

Received: October 22, 2020

Accepted: December 18, 2020

Published: December 21, 2020

Copyright (อ 2020 by author(s) and Scientific Research Publishing Inc. This work is licensed under the Creative Commons Attribution International License (CC BY 4.0).

http://creativecommons.org/licenses/by/4.0/ (c) (i) Open Access

\begin{abstract}
Introduction: During childbirth by Caesarean, several types of anesthesia can be used. The Caesarean, the most practiced surgical delivery technique in obstetrics, has a risk for complications for both the pregnant women and newborns. Objective: To evaluate the importance of the complications due to Caesarean in the Teaching hospital Gabriel Toure. Patient and Methods: We conducted a cross sectional survey in the departments of intensive care unit and gyneco-obstetric from January to August 2017 in the University hospital Gabriel Touré of Bamako. Our study population was pregnant women who gave birth to children by Caesarean. We included all cases of preventive and emergent Caesarean under loco-regional or general anesthesia. Data were compiled from the obstetrical files of the patients, the anesthetic consultation registry and the databasis of the department of gyneco-obstetric. The test of $\mathrm{khi}^{2}$ of Pearson was used for the comparison of our results with a value of $\mathrm{p}<$ 0.05 considered as statistically significant. The consent of the patients or parents was gotten. The survey didn't include a potentially dangerous act. Results: During the study period, 1875 childbirths have been recorded of which 633 were by Caesarean (33.7\%). We collected and analyzed 524 files of Caesarean. The mortality rate was $1.5 \%$ in pregnant women and $15 \%$ in newborns. The average age was $26.6 \pm 6.9$ ans. Pregnant women were referrals in $59.4 \%$ of the cases. The most frequent motive of referrals was high blood
\end{abstract}


pressure and pregnancy in $66.6 \%$. The Caesarean was indicated in most of the cases on previously operated uterus in $22 \%$ and eclampsia was present in $14 \%$. The maternal mortality had occurred in a context of hemorrhage in $50 \%$ of the cases. The factors of maternal morbi-mortality were the mode of admission, iterative Caesarean, $t$ surgeon, context of the Caesarean, realization of the anesthetic consultation and the technic of anesthesia $(p=0.05)$. The factors of fetal mortality were the realization of endo-tracheal intubation, technic of anesthesia, realization of the anesthesia consultation, context of the Caesarean, iterative Caesarean and the mode of admission ( $\mathrm{p} \leq 0.05)$. Conclusion: The caesarean is associated with a high risk of maternal complications and a very important fetal mortality. The anesthesia consultation in the follow-up of pregnancy would reduce this high mortality.

\section{Keywords}

Morbi-Mortality Materno-Fetal, Peri-Operative, Caesarean, Mali

\section{Introduction}

The Caesarean section is one option of childbirth, which is used every time that the childbirth by natural route constitutes a risk for either the fetus and/or the mother. However, it sometimes entails a circumstance of morbidity and mortality [1]. The National Committee of experts on the Maternal Mortality (CNEMM) in France had kept during the period 2001-2006, seven maternal deaths classified as complications of anesthesia with a global maternal mortality rate of $0.14 / 100,000$ births [2]. In 1985, the WHO had recommended that the national rates of Caesareans must be located reasonably between $10 \%$ and $15 \%$ of the child deliveries. The rationale for that is pregnancy and the childbirth is physiological phenomena and that the dystocia remains the exception and would not go over the middle rates of $10 \%$, but this is not the case nowadays. Indeed, one notes that the childbirth rates by Caesarean increased continually during these last decades worldwide [3] [4]. This high rate is not only due to the evolution of the society, but also especially to the obsessions of obstetricians to deliver newborns in the best health conditions, and to preserve the mother's comfort and good health [5]. Consequently, the Caesarean seems to become the inescapable surgical technique to limit the dystocia and obstetric difficulties. Caesarean evolves from an exceptional surgical intervention to nearly a routine intervention worldwide [6]. Cesarean is the most practiced intervention in obstetrics, it can be either a programmed (prophylactic) intervention in previously informed and consented pregnant women or emergent in life threatening situations as far as the materno-fetal prognosis is engaged. Caesarean results in more materno-fetal complications as compared to physiological delivery by lower genital route. Its perioperative indications must always be justified [7]. The objective was to evaluate the importance of the complications due to Caesarean in the University hospital Gabriel Toure. 


\section{Patient and Methods}

We conducted a cross sectional survey from January to August 2017. The study population was pregnant women who gave birth by Caesarean under loco regional or general anesthesia and hospitalized in the departments of gyneco-obstetric and intensive care unit of the University hospital Gabriel Toure. We did exclude those whose obstetric files and/or anesthesia file was not available. The variables were the sociodemographic characteristic and maternal clinics and the state of the newborns. The parturientes and the newborns had benefitted from a regular surveillance. The parturientes were followed in per and postoperative period in order to value the evolution. The Apgar score was used to evaluate the newborns state. The collected informations were consigned in a questionnaire.

The data entry and analysis have been done with the software SPSS version 22.0. The used statistical tests were: the $\mathrm{khi}^{2}$ of Pearson, the correction of continuity and the exact test of Fisher, with a value of $p<0.05$ was considered as statistically significant. The consent of the patients or parents was gotten. The survey didn't include any potentially dangerous act.

\section{Results}

During the study period, out of 1875 childbirths, 633 cases of Caesarean have been recorded. This is a frequency of $33.7 \%$. The files of 524 pregnant women have been collected of which 158 had presented at least one complication (30.2\%). The average age was of $26.6 \pm 6.8$ years with the extremes of 15 and 47 years. Mortality rate was of $1.5 \%$ in mothers. The prognosis of the newborns is mentioned in Figure 1. The women didn't have a paid employment in $65.6 \%$. The modes of admission were the evacuation in emergency (59.4\%), prophylactic caesarean $(22.5 \%)$, and referrals $(18.1 \%)$. The three main motives of admission were eclampsia of the prepartum (23.5\%), pre-eclampsia $(22.8 \%)$ and retroplacental hematoma (20.6\%). Referrals were from the district health centers in $85.2 \%$. The familial history of high blood pressure was noted in $62.3 \%$, the personal history of high blood pressure in $52.3 \%$ and the iterative Caesarean in $34.7 \%$. The paucigestes and the paucipares predominated with $33 \%$ and $30.1 \%$, respectively. Pregnant women had undergone at least a previous Caesarean in $55.5 \%$ of the cases. The prenatal follow-up was achieved in $60 \%$. Pregnant women were followed up by midwives in $43.3 \%$, gynecologists' obstetricians in $26.1 \%$, general practitioners in $24.5 \%$, residents in $4.2 \%$ and aid midwives in $1.3 \%$.

At admission, vital parameters were normal as followed: body temperature (87.4\%), heart rate (HR) 69.7\%, respiratory frequency (FR) in 56.3\%, diastolic arterial pressure (59.9\%) and systolic arterial pressure (51.7\%). At admission, $80 \%$ of pregnant women had a normal Glasgow score; $78.4 \%$ had the colorful conjunctive; $37.8 \%$ were in overweight; $78.4 \%$ had no edema of the lower limbs; 99.2\% had jaundice. The Caesarean was achieved in emergency in $84.9 \%$ of the 
cases. The four main indications of the Caesarean were previous caesarean (22\%), eclampsia (14.1\%), retro placental hematoma (HRP): $11.3 \%$, severe pre-eclampsia and the acute fetal suffering. (10\%) The average delay between the diagnosis and the Caesarean was 2.04 hour with the extremes of 1 and 14 hours (Table 1).

Caesarean was achieved in $89 \%$ by the residents in gyneco-obstetrics. Anesthesia was carried out by nurses in $71.2 \%$ of the cases. The pre-surgery consultation of anesthesia was not possible in $90.3 \%$ of the cases. Anesthetic techniques used were rachianesthesia (54.2\%), general anesthesia (44.3\%) and the epidural (1.5\%). The observed peroperative morbid events were cardiovascular, respiratory, hemorrhagic and renal with respectively $71.8 \%, 17.4 \%$ and $10.8 \%$. The observed postoperative morbid events were cardiovascular, respiratory, neurological, infectious and other (CIVD, hyperglyceamia, anemia and vomitings) with respectively $38.7 \% ; 11 \% ; 23.3 \% ; 1.7 \%$ and $25.3 \%$. The thrombo-prophylaxis was used in $13.2 \%$ and multimodal analgesia was in $20 \%$ of the cases. The maternal deaths occurred during resuscitation in $75 \%$ due to hemorrhage (50\%), eclampsia (25\%), HELLP syndrome (12.5\%) and disseminated intravenous coagulation (CIVD) $(12.5 \%)$. fetal death was in utero in $92.5 \%$ and due to the respiratory distress in $7.5 \%$.

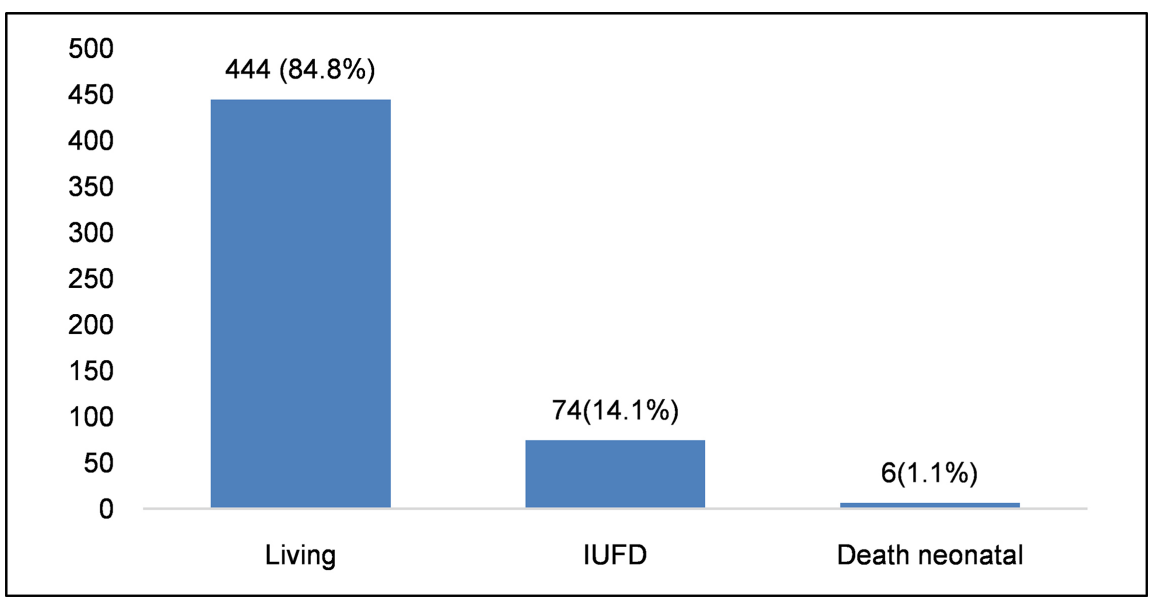

Figure 1. Prognosis of the newborns. IUFD (In utero fetal death).

Table 1. Time of decision making to caesarean realisation.

\begin{tabular}{ccc}
\hline $\begin{array}{c}\text { Delay of decision making and the incision: } \\
\text { Caesarean of emergency (in hour) }\end{array}$ & $(\mathrm{n}=445)$ & $\%$ \\
\hline 1 & 228 & 51.2 \\
2 & 108 & $2 ., 3$ \\
4 & 49 & 11 \\
5 & 24 & 5.4 \\
6 and + & 14 & 3.1 \\
\hline
\end{tabular}

Delay $\min =1 \mathrm{~h}$; Delay $\max =14 \mathrm{~h}$; average delay $=2.04 \mathrm{~h}$; Gap marks $=1.574$. 
The maternal and fetal mortality rates were $2.3 \%$ and $24.7 \%$ in referred pregnant women from outside Bamako and $1.1 \%$ and $0 \%$ in referrals within Bamako, $0 \%$ and $2.5 \%$ in prophylactic caesarean in walk-in pregnant women $(\mathrm{p}<0.001)$. Morbid events long distance referrals, referrals from Bamako and walk-in pregnant women were $42.4 \%, 12.7 \%$ and $11.6 \%$, respectively ( $\mathrm{p}<0.001$ ). The maternal death occurred in $0.5 \%$ of the cases of iterative Caesarean against $2 \%$ of non-iterative Caesarean $(\mathrm{p}=0.27)$. The foetal death occurred in $7.7 \%$ in case of iterative Caesarean against $21.3 \%(\mathrm{p}=0.001)$. Also, the contribution of the morbid factors was more important in case of non-iterative $(34.7 \%)$ versus iterative caesarean $(22 \%) \mathrm{p}=0.003$. The maternal mortality rate was higher in emergency caesarean as compared to prophylactic caesarean $(1.8 \%$ versus $0 \%) \mathrm{p}=$ 0.61 . The fetal mortality rate was higher in emergency caesarean as compared to prophylactic caesarean $(17.4 \%$ versus $2.5 \%)(\mathrm{p}=0.001)$. The complications and maternal deaths were more frequent when the surgeon was a resident in gyneco-obstetrics as compared to a certified gynecologist obstetrician $(32.2 \%$ versus $13.8 \%) \mathrm{p}=0.004$ and $(15.7 \%$ versus $0 \%) \mathrm{p}=0.60$. The fotal death rate was also slightly higher with a resident as the surgeon as compared to a certified gynecologist obstetrician (15.7\% versus $12.1 \%) \mathrm{p}=0.85$.

The morbid events occurred when the anesthetist in a physician in $20 \%$, a nurse in $29.2 \%$ and a resident in intensive care in $32.9 \% \mathrm{p}=0.65$. Without and with preoperative anesthesic consultation, maternal mortality rate was $1.7 \%$ versus $0 \%(\mathrm{p}=1)$, in utero death was $15.6 \%$ versus $0 \%(\mathrm{p}=0.001)$, complications were more frequent $32.3 \%$ versus $9.8 \%(\mathrm{p}=0.001)$. All maternal deaths had occurred after general anesthesia $(\mathrm{p}=0.004)$. The fetal death was more frequent in general anesthesia as compared to rachianesthesia $14.4 \%$ versus $4.2 \%$. No fetal death occurred with epidural anesthesia ( $p<001$ ). Complications were the highest in general anesthesia 42.2\%, 20.8\% in rachianesthésia and the lowest epidural anesthesia $12.5 \%(\mathrm{p}=0.001)$. The main factors of maternal mortality and fetal are mentioned in Table 2 and Table 3.

Table 2. Factors of risk maternal mortality.

\begin{tabular}{|c|c|c|c|c|}
\hline \multirow{3}{*}{ Anesthesia Technic } & \multicolumn{2}{|c|}{ Parameters } & \multirow{3}{*}{ Total (\%) } & $\mathbf{P}$ \\
\hline & \multicolumn{2}{|c|}{ Maternal Prognosis } & & \multirow{6}{*}{0.004} \\
\hline & Live (\%) & Death (\%) & & \\
\hline Epidural & $8(100)$ & $0(0)$ & $8(1.5)$ & \\
\hline $\mathrm{AR}$ & $284(100)$ & $0(0)$ & $284(54.2)$ & \\
\hline GA & $224(96.6)$ & $8(3.4)$ & $232(44.3)$ & \\
\hline Total & $516(98.5)$ & $8(1.5)$ & $524(100)$ & \\
\hline \multirow{2}{*}{ Intubation } & \multicolumn{2}{|c|}{ Maternal Prognosis } & TT 1 ( ) & \multirow{5}{*}{0.005} \\
\hline & Live (\%) & Death (\%) & 10 (a) $(0)$ & \\
\hline Yes & $224(96.6)$ & $8(3.4)$ & $232(44.3)$ & \\
\hline No & $292(100)$ & $0(0)$ & $292(55.7)$ & \\
\hline Total & $516(98.5)$ & $8(1.5)$ & $524(100)$ & \\
\hline
\end{tabular}


Table 3. Factors of risk of mortality fetal.

\begin{tabular}{|c|c|c|c|c|}
\hline \multicolumn{4}{|c|}{ Parameters } & $\mathbf{P}$ \\
\hline \multirow{2}{*}{ Fashion of admission } & \multicolumn{3}{|c|}{ Fetal prognosis } & \multirow{6}{*}{$<0.001$} \\
\hline & Live (\%) & IUFD (\%) & Neonatal death (\%) & \\
\hline Referred to cold weather & $95(100)$ & $0(0)$ & $0(0)$ & \\
\hline Come of herself & $115(97.5)$ & $3(2.5)$ & $0(0)$ & \\
\hline Evacuated & $234(75.2)$ & $71(22.8)$ & $6(1.9)$ & \\
\hline Total & $444(84.7)$ & $74(14.1)$ & $6(1.2)$ & \\
\hline \multirow{2}{*}{ ATCD of Caesarean } & \multicolumn{3}{|c|}{ Fetal prognosis } & \multirow{5}{*}{0.001} \\
\hline & Live (\%) & IUFD (\%) & Neonatal death (\%) & \\
\hline Yes & $168(92.3)$ & $14(7.7)$ & $0(0)$ & \\
\hline No & $276(80.7)$ & $60(17.5)$ & $6(1.8)$ & \\
\hline Total & $444(84.7)$ & $74(14.1)$ & $6(1.2)$ & \\
\hline \multirow{2}{*}{$\begin{array}{l}\text { Context of the } \\
\text { Caesarean }\end{array}$} & \multicolumn{3}{|c|}{ Fetal prognosis } & \multirow{5}{*}{0.001} \\
\hline & Live (\%) & IUFD (\%) & Neonatal death (\%) & \\
\hline Emergency & $367(82.5)$ & $72(16.2)$ & $6(1.3)$ & \\
\hline Programmed & $77(97.5)$ & $2(2.5)$ & $0(0)$ & \\
\hline Total & $444(84.7)$ & $74(14.1)$ & $6(1.2)$ & \\
\hline \multirow{2}{*}{ Anesthesia technic } & \multicolumn{3}{|c|}{ Fetal prognosis } & \multirow{6}{*}{$<0.001$} \\
\hline & Live (\%) & IUFD (\%) & Neonatal death (\%) & \\
\hline Epidural & $8(100)$ & $0(0)$ & $0(0)$ & \\
\hline $\mathrm{AR}$ & $272(95.8)$ & $12(4.2)$ & $0(0)$ & \\
\hline GA & $164(70.7)$ & $62(11.8)$ & $6(2,6)$ & \\
\hline Total & $444(84.7)$ & $74(14.1)$ & $6(1.2)$ & \\
\hline \multirow{2}{*}{ Intubation } & \multicolumn{3}{|c|}{ Fetal prognosis } & \multirow{5}{*}{$<0.001$} \\
\hline & Live (\%) & IUFD (\%) & Neonatal death (\%) & \\
\hline Yes & $164(70.7)$ & $62(26.7)$ & $6(2.6)$ & \\
\hline No & $280(95.9)$ & $12(4.1)$ & $0(0)$ & \\
\hline Total & $444(84.7)$ & $74(14.1)$ & $6(1.2)$ & \\
\hline
\end{tabular}

\section{Discussion}

This survey allowed us to evaluate the level of the risk relaled to the Caesarean in our context. However, these results don't reflect the totality of the Caesareans because of the quality of the follow-up files. All patient files could not be used to collect data. The limits were: the follow-up irregular of the files, the medical aid absence to the poor parturientes, the weak presence of the physicians anesthetists at the time of the Caesareans. Staff's lack explains in big parts these insufficiencies. The prevalence of $33.76 \%$ of Caesarean is similar to the rate found by Samaké B.M. [4]. One or more morbid complications occurred in $30.2 \%$ of the 
pregnant women. This rate is extensively superior to $12.4 \%$ reported in the retrospective survey in Casablanca between 1994-1997 on the maternal complications of the Caesarean [7]. Despite the materno-infantile lifesaving label in numerous situations, Caesarean comes with a materno-fetal mortality and morbidity rates higher than those in natural childbirths. Its indications must always be justified.

The tachycardia found to be the most frequent morbid event in preoperative period. This may be due to the unavailability of opioids resulting in its inappropriate use at insufficient doses before and during cesarean. The letality rate was of $1.5 \%$ versus $5.2 \%$ reported by Samaké B.M. [4]. This difference may be explained by the quality of the anesthesia. In this study, general anesthesia was done under endotracheal intubation in $100 \%$ whereas intubation was not done in the series of Samaké B.M. in 88.5\% [4]. In ceasarean, the causes of maternal deaths are multiple and can be attributable to either anesthesia or the surgery itself. A survey made in the United States from 1991 to 2002 showed that $1.6 \%$ of the maternal deaths are due to the anesthesia [8] and the ratio of mortality is of 1.2 per million living births. A similar rate using a different estimation method over three years was reported from the United Kingdom [8]. Despite the difference in the length of the study and the quality of the data, maternal mortality rates from both studies are in conformity with the WHO reports. Every year, about eight millions of women are victims of pregnancy complications with over a million deaths worldwide [9].

The Caesarean is mainly indicated in case of hypertensive pathology among including eclampsia. The contributing factors to eclamptic crises could be due to either low socioeconomic levels or young gestationnel age. Maria B. [10] also concluded maternal age less than 20 years and the lack of prenatal surveillance were risk factors for eclampsia in her study. The bleeding was an important reason of maternal mortality (50\%) and morbidity. It can be of uterine origin (by rupture or inertia), of placental origin (placenta prævia or placenta accreta), of traumatic origin or in relation with general factors as the hematosis impairment.

Only $6.7 \%$ of pregnant women were single. Unmarried status in the Malian society could be a factor of risk of maternal deaths. Solidarity is essentially formed around the couple for the expenses of a married woman in need of ceasarean while an unmarried woman may find it difficult to make it by herself.

The maternal death rate was not statistically associated with the mode of admission of the pregnant women. It was nevertheless slightly more important with long distance referrals in emergency setting $(p=0.24)$. The relationship between the fetal death and the mode of admission of the pregnant women was statistically significant $(\mathrm{p}=0.0001)$. No fetal death was reported in a non-emergent referral. The contribution of the morbid events is also due to the emergency evacuation as mode of admission $(\mathrm{p}=0.0001)$. These results emphasize the impact of poorly organized evacuations of pregnant women and highlight the necessity of an obstetric follow-up coupled with a strong involvement of the dis- 
trict health center in each commune of Bamako. Maternal death is not due to the iterative character of the Caesarean. However, both morbid events and fotal deaths were associated with the iterative character of the Caesarean $(p<0.05)$. The morbid events and the fotal deaths were less frequent when the pregnant women had already undergone a previous Caesarean. A history of previous Caesarean raises the alertness of the care givers and results usually in prophylactic caesarean. The context of the Caesarean (urgent or programmed) is susceptible to influence the maternal mortality, what we didn't find ( $\mathrm{p}=0.61$ ). However, it influences the fetal prognosis. In case of Caesarean in emergency, we observed $17.4 \%$ of fotal death versus $2.5 \%(\mathrm{p}=0.001)$. When the Caesarean is achieved in emergency, the delay of care is a determining factor of the maternofœtal deaths, and the occurrence of morbid events. The morbid events are more frequent with the residents than with cerfitied gynecologists obstetricians with $\mathrm{p}<0.05$. The maternofoetal deaths were not correlated with the qualification of the surgeron with $\mathrm{p}>0.05$. The morbid events, maternal and fotal deaths had nostatistically significant association with the qualifications of the anesthetists either. Morbid events and foetal deaths correlated with the realization of the anesthesia consultation with $\mathrm{p}<0.05$. Maternal deaths were not statistically associated with the realization of the anesthesia consultation, even though that the consultation permits to evalue the risk for pregnant women to have ceasarean. It could be explained by the young age of our study population without factors of comorbidity. All maternal deaths the quasi-totality of the fotal deaths and more of two third of the morbid events occurred with general anesthesia $(\mathrm{p}<0.05)$. This was similar to the findings from the literature suggesting that the time of the general anesthesia is a major determining factor of the materno-fotal deaths.

\section{Conclusions}

The rate of morbimortality was very high during the Caesarean in the University hospital Gabriel Toure. We recommend correct follow-up of pregnancies, the realization of the anesthesia consultation by all pregnant women at risk before the labor for childbirth.

In spite of these prenatal precautions, the foto-maternal morbimortality risk will still exist. Emergency care should be well organized to bring the care closer to the pregnant women, to train sufficient qualified staff, and to make medicines available to patients. This will shorten the delays of care and improve the quality of the care conform to the international norms.

\section{Conflicts of Interest}

The authors declare no conflicts of interest regarding the publication of this paper.

\section{References}

[1] Diallo, F.B., Diallo, M.S., Bangoura, S., Diallo, A.B. and Camara, Y. (1998) 
Césarienne: Facteurs de réduction de morbidité et de mortalité fœeto-maternelle au centre hospitalier universitaire Ignace de Conakry. Médecine d' Afrique Noire, 45, 359-364.

[2] Saucedo, M., Deuneux-Tharaux, C. and Bouvier-Colle, M. (2010) La mortalité maternelle en France: Bilan 2001-2006. BEH 19 janvier, №2-3.

[3] Blondel, B., Lelong, N., Kermarrec, M. and Goffinet, F. (2012) Trends in Perinatal Health in France from 1995 to 2010. Results from the French National Perinatal Surveys. Journal de Gynécologie Obstétrique et Biologie de la Reproduction, 41, 1-15. https://doi.org/10.1016/j.jgyn.2012.04.014

[4] Samaké, B.M., Traoré, Y., Niani, M., Kéïta, M., Kéita, B., Togola, M., Mangané, M., Alméïmoune, H., Tekété, I. and Doumbia, D. (2017) Facteurs de morbi-mortalité de la césarienne au centre hospitalier universitaire Gabriel Touré MALI MEDICAL. TOME XXXII N².

[5] Enquête démographique et de santé MALI V. EDSM-V de 2012-2013:111.

[6] Driscoll, O. and Foel, Y. (1983) Correlation of Decrease in Prenatal Mortality and Increase in C-Section Rates. Am. J. obstet. Gynecol, 61, 1.

[7] Abrassi, H., Aboulfalah, A., Morsad, F., Matar, N., Himmia, El. and Mansouri, A. (2000) Complications maternelles des césariennes: Analyse rétrospective de 3231 interventions à la maternité universitaire de Novembre à Décembre $2000 \mathrm{de}$ Casablanca. Maroc Santé, 10, 419-423.

[8] Joy, L., Hawkins, M.D., Jeani, C., Susan, K., Palmer, M.D., Charles, P., et al. (2011) Anesthesia-Related Maternal Mortality in the United States: 1979-2002. Obstetrics Gynecology, 117, 69-74. https://doi.org/10.1097/AOG.0b013e31820093a9

[9] OMS (2004) Au-delà des nombres, examiner les morts maternelles et les complications pour réduire les risques lies a la grossesse. Genève, Suisse, 4 .

[10] Maria, B. (2001) Mortalité maternelle: Les complications obstétricales évitables. Journal de Gynécologie Obstétrique et Biologie de la Reproduction, 6, 232. 